Title: $\quad$ Non-Visual Aesthetics: Seeing the World with Our Bodies

Author: Anthony Schrag

Address: Queen Margaret University

Musselburgh

Edinburgh,

EH21 6UU

e: $\quad$ aschrag@qmu.ac.uk

$\mathrm{t}: \quad+44(0) 1314740000$

Word Length: 6926

7027 with footnotes

7636 with bibliography

Biography: Anthony Schrag is an artist and researcher working both nationally and internationally, including residencies in Iceland, USA, Canada, Finland, Holland and South Africa. His practice occurs in participatory manner, and central to his work is a broader discussion about the place of art in a social context. He has been the recipient of numerous awards, commissions and exhibitions and his practice-based $\mathrm{PhD}$ explored the relationship between artists, institutions and the public, looking specifically at the productive nature of conflict. The artist Nathalie De Brie once referred to his practice as 'Fearless'. The writer Marjorie Celona once said: 'Anthony, you have a lot of ideas. Not all of them are good.' 


\section{Non-Visual Aesthetics: Seeing the World with Our Bodies}

\section{Abstract:}

This text explores the role of 'physical ontologies' within Socially Engaged Art practices, and explores how the notion of visual art can be limiting to artworks developed with communities and 'non-artists'. It uses the field of Embodied Cognition and the concept of an Anthropology of the Body to frame how physical activities can be positioned not only as 'art' but as processes by which artists can ethically explore the world with communities. As such, it provides a counter-narrative to assumptions of how art should function within socially engaged contexts, and examines how physical ontologies become effective - and affective - tools when working in genre of art that is fundamentally based on humans exchanging with each other in a process meaning-making.

While there are many discussions on-going about the role of art within the public realm, the formulation of a physical ontology within socially engaged practices has been less explored, and this text provides a reflective discussion point. It is written from the perspective of a practice-based researcher who has worked within the field of participatory/public art for over 14 years, and provides an example of a physical methodology to frame his argument.

This information would be important and interesting for any fields or practitioners working in an engaged or participatory manner with an artist, such as social work, participatory democracy/activisms, or other socially engaged practices.

Keywords: Participatory Arts; Embodied Cognition, The Anthropology of The Body, Socially Engaged Art, Physical Ontologies, Non-Visual Art. 


\section{Non-Visual Aesthetics: Seeing the World with Our Bodies}

\section{1) Introduction: Non-Visual Aesthetic Ontologies}

Clement Greenberg famously demanded art only be a visual medium and that "art should confine itself exclusively to what is given in visual experience, and make no reference to anything given in any other order of experience," 1 and that we should access art by "eyesight alone."2 While this is a dated notion and current concerns with the body (i.e., performance art, sensory works or aural/sound art) as well as concepts of materiality and affect explore the non-visual elements within art, however this hangover from Modernism still lingers and the expectation that art is/should be predominately visual still lies at the core of our cultural experiences - consider our language: We go to see a sculpture; We watch a play/film; We look at some art in a gallery.

It is beyond the scope of this text to cover the entire 'what is art?' discourse, but I will frame my definition via the Canadian artist Liz Magor who said: "art is the thing that challenges our perceptual habits." To me, this succinctly defines the purpose and function of contemporary art, clarifying that art is always contextual and based upon conceptual processes, rather than something which is medium specific. For example, Picasso challenged the visual perceptual habits of the early 20th century as well as the appropriate subject of a painting; Damian Hirst's formaldehyde shark challenged perceptual habits of sculpture and but also concerns of authorship and commerce; Marina Abramovic's work of the 1960s and 70s challenged the perceptual habits of performance, as well as complicating the relationship between art and 'representation' as she experienced very real pain in her works, rather than just representing it. In these examples, art occurs as a process of thinking and unravelling the world. It is not just an expression but a challenge to think differently. In this way, there is indeed a form - often visual - of art, but this form is a clue to the concepts behind it. It therefore not what we see but what we think that is important.
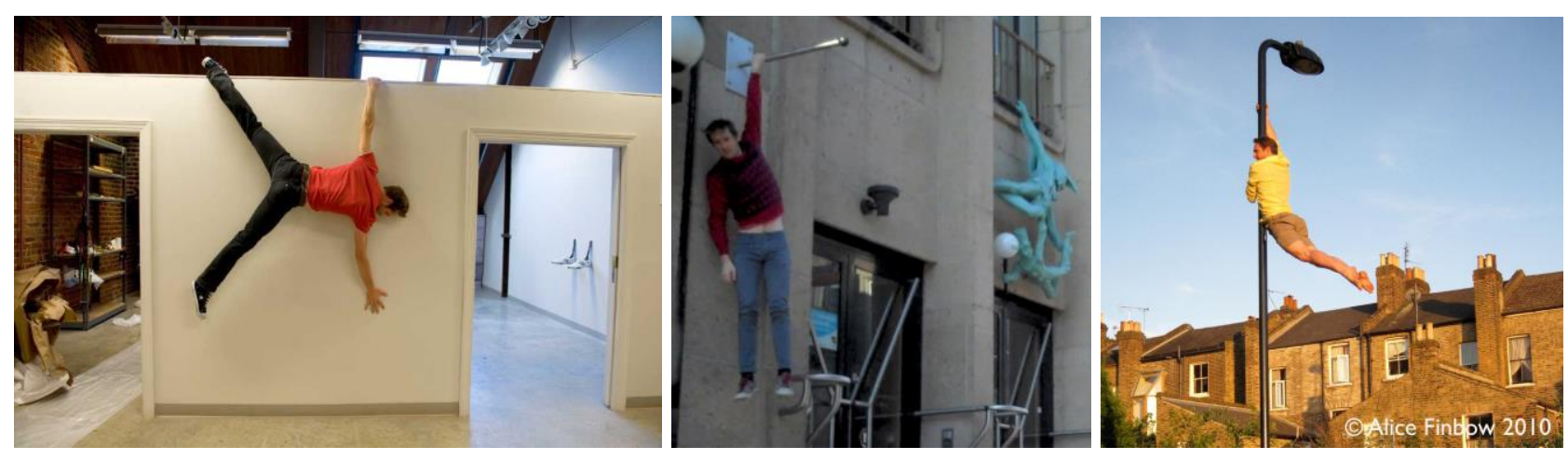

Fig 1.1 Wall Hanging. Digital Image - documentation of performance. 2012. (Photo by Ben Premeaux)

Fig 1.2 Things To Do - Enschede. Video Still - documentation of performance. 2010.

Fig 1.3 Flag. Digital Image - documentation of performance. 2010. (Photo by Alice Finbow)

As an artist, I have always found the 'visual' form problematic and trace this to my terrible eye-sight. Before laser surgery in my late 20 s, anything beyond my outstretched hand was a blur: formless, inaccessible and uninteresting. Growing up, I interfaced with the world via my body not my eyes, driven by corporeal senses, and engaging in dance, gymnastics and sports. In Art School, I thankfully had tutors who encouraged to lean towards this unique perspective, and they helped me develop works that explored 'corporality' in performances and physical events. In retrospect, I now understand the works I made were a process of thinking which aimed to challenge the habits of a body in the public realm, inquiring into a body's relationship to architecture and the constructed environment (examples in Figs $1.1-1.3$ ). I was interested in the notion of the functionality and

\footnotetext{
${ }^{1}$ C. Greenberg. (1960) Forum Lectures. Washington, D. C.: Voice of America.

2 C. Greenberg. (1993) 'Sculpture in our time,' in J. O'Brian (ed.)1993 C. Greenberg, Collected Essays and Criticism, Volume 4. Chicago. The University of Chicago Press. p. 70.

${ }^{3}$ Liz Magor, 2002, in conversation with Author. Vancouver, BC.
} 
potentiality of our bodies: bodies that had evolved to climb, to hunt and generally be far more active than it is in our Western, sedentary lifestyles. ${ }^{4}$

The work had developed intuitively, but had been rationalised via an understanding of Mirror Neurones, which are "a distinctive class of neurones that discharge both when an animal executes a motor act and when it observes another individual performing the same or a similar motor act." ${ }^{5}$ In simpler terms, Mirror Neurones are "activated both when you do something, as well as when you watch something... any action that we watch may be mirrored, and in some sense acted out, inside of our own brains." 6 This means that if a person were to witness someone else jumping, for example, his or her Mirror Neurones would replicate that action in the brain as if he/she were actually jumping, too. This neurological process has been claimed to be the single most important development in human civilisation as "our ability to learn skills via imitation, use language as a communicative tool, and sense what others are thinking and feeling"7 is dependent on this process. Importantly, this suggests it is a physical process by which we enact/understand social relationships. I shall return to this concept below.

I continued to make work that stemmed from physical ontologies, and in 2003 , they began to be more participatory, more 'socially engaged'. For example, in 2005, I was invited to develop a work for a community in Glasgow that was known for its violence. However, as an outsider to that community, I did not feel that could appropriately make comments or judgements on the issue, and instead wanted to find a way to speak about the issues of violence with the community. Therefore, one afternoon with colourful balloons filled with sweets fixed onto a protective foam armour, and dangling from a large bungee chord, I invited passing community members to beat me with sticks, as one would hit a piñata. Called The Human Piñata, I wanted the work to explore new imaginaries on the subject of violence and collaboratively explore the subject in both a direct, but also physical way. Rather than looking at a work about violence, the community and I were engaged in (safe) physical forum about violence. The aim was to have a shared, physical experience, and through physically-induced affective processes, collaboratively considering the world anew.

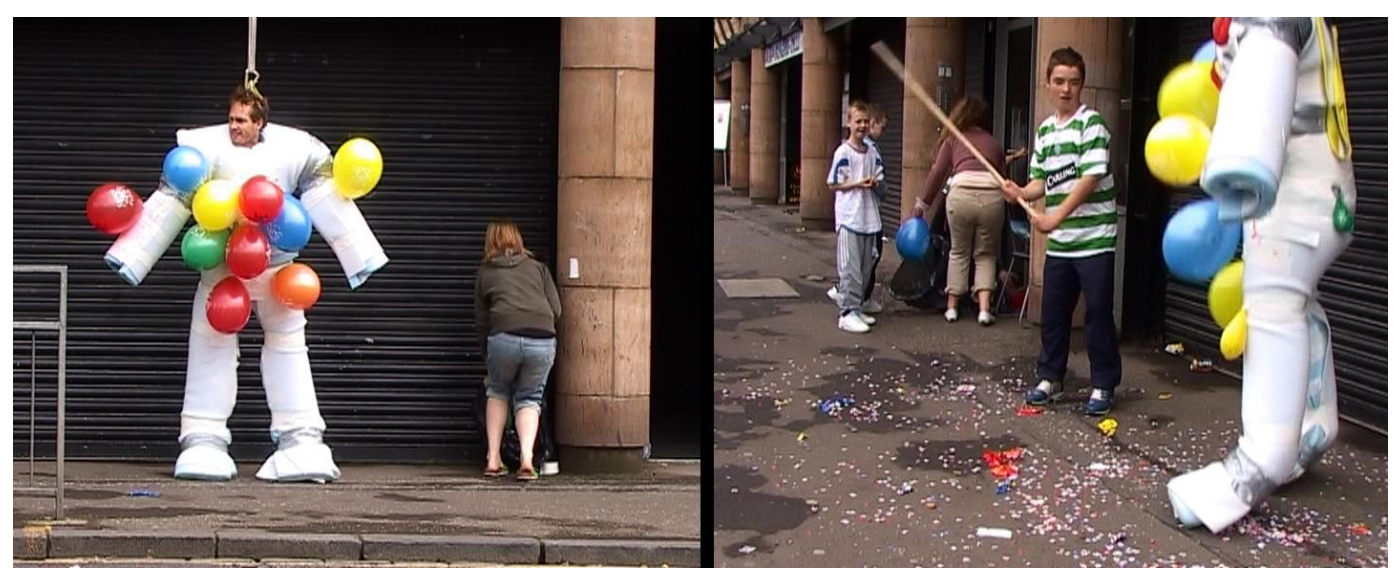

Fig 1.4 The Human Pinata. Video Stills - documentation of performance. 2005.

\footnotetext{
${ }^{4}$ A. Alvarez. (2012) 'Sedentary lifestyle not to blame for obesity' Journal Sentinel. http://www.jsonline.com/news/health/sedentary-lifestyle-not-to-blame-for-obesity-2868cb8-163809356.html. July 26, 2012. (Accessed 6 January, 2017) and M. Martinez-Gonzalez, J. Martinez, F. Hu, M. Gibney, J. Kerney, (1999) 'Physical inactivity, sedentary lifestyle and obesity in the European Union.' International Journal of Obesity Related Metabolic Disorders. 23:11. pp. 1192 - 1201. \& S. Lees, \& F. Booth. (2004) 'Sedentary Death Syndrome'. Canadian Journal of Applied Physiology, 2004, 29:4. pp. 447 - 460.

5 G. Rizzolatti \& M. Fabbri Destro (2008) 'Mirror Neurones' Scholarpedia, 3(1): 2055.

6 D. Peterson (n.d.) 'Mirror Neurons \& Athletes: Learning by Watching'. Axon Potential. http://www.axonpotential.com/mirror-neurons-and-athletes. (Accessed 12 January, 2017)

${ }^{7}$ Ibid.
} 
The desire for artists to 'work with people' is not new urge. While we currently refer to this practice as "Socially Engaged Art" (SEA) its lineage over the past 120 years is vast and includes largescale community re-creations of revolutionary successes in Russia in the 1900s; the Futurists' bombastic performances of the 20s; the public events held by Situationists in the 30s; the Happenings of the 50s; the experimental research of G.R.A.V. in the 1950s; the community embedded work of the Community Arts Movement within the UK of the 1960s; the ground-breaking work of the Artist Placement Group in the 1970s; the resistance theatre of Paulo Friere in the 80s; Suzanne Lacy's work with Black youth in Oakland in the 90s; Jeremy Deller's re-staging of recent political riots in 2000; as well as current projects such as Rick Lowe's Project Row Houses. It is therefore not a new art form. However, considering the recent political emphasis on widening participation and engagement policies ${ }^{9}$ - from everything including citizen budgeting and economics ${ }^{10}$, to environmental action, ${ }^{11}$ to even religion ${ }^{12}$ - the role of art within the public realm is becoming both more supported and popular, but also more instrumentalised. ${ }^{13}$

Like the definition of 'art', however, it is not within the scope of this paper to fully explore the history of this work and unravel its issues of instrumentalisation, but it is important for this paper to define and frame the practice. As such: SEA consists of artworks which commit to the engagement of and co-authorship with others and they are developed with groups and/or individuals. The Tate Gallery's website clarifies: "Socially engaged practice...can include any artform which involves people and communities in debate, collaboration or social interaction. The participatory element of socially engaged practice, is key, with the artworks created often holding equal or less importance to the collaborative act of creating them." 14 In other words, just as paintings can explore an idea or feeling, so too can activities and events. The art of SEA lies within the exchanges and relationships, and as such is highly concerned with the ethics of social structures. It is a collective meaningmaking, rather than a focus on producing traditional artefacts.

There are many forms and models of Social Engagement, including the visual (i.e., the Docklands Community Poster Project (1981-1988) in which artists Peter Dunn and Lorraine Leeson worked with a local community develop large scale images that protested the gentrification of the area); or the sculptural (i.e., in the 1970s David Harding worked with school children in Glenrothes to collectively develop sculptural elements for their playground and school); or the dialogic approach (advocated by theorist Grant Kester, such as Adrian Piper's Calling Card in which the artist gave members of the public small business cards on which was printed 'controversial' subject matter in order to elicit conversation about the subject), to name but a few. However, the place and role of a physical ontology within SEA has been less explored, and I will spend the rest of this text exploring two concepts that frame the collective meaning-making along corporeal lines within SEA projects.

\section{1) Embodied Cognition}

\footnotetext{
${ }^{8}$ I recognise this is a problematic term due to its implication that 1) people are not already socially engaged, and 2) it implies a certain cultural colonisation, not to mention the embedded neoliberal notions when applied within the context of New Labours Social Inclusion policies (See Levitas, 2002). I personally prefer the term Participatory Practices.

9 “....Beginning of the 1990s a new discourse emerged...insisting on the necessity of 'civil society' participation in decision-making processes... [and] the emergence of this participatory turn in the official discourse and its transformation into a norm." S. Saurugger. (2010) 'The social construction of the participatory turn: The emergence of a norm in the European Union'. European Journal of Political Research. Volume 49, Issue 4. Pages 471-495.

10 'Edinburgh's Budget Challenge' (n.d.) Edinburgh Council Website: https://consultationhub.edinburgh.gov.uk/cg/budget/ (Accessed May 25, 2017)

11 'Public Participation Guide: Introduction to Public Participation' (n.d.) Environmental Protection Agency: https://www.epa.gov/international-cooperation/public-participation-guide-introduction-public-participation (Accessed May 25, 2017)

12 'The Participatory Turn: Spirituality, Mysticism, Religious Studies' (n.d.) Suny Press Website:

http://www.sunypress.edu/p-4687-the-participatory-turn.aspx (Accessed May 25, 2017)

13 There are many critiques of the 'social inclusion approach' and see for example S. Hope (2012), R. Levitas (2002), A Hewitt (2011) or E. Belfiore (2002) for an overview.

14 'Socially Engaged Practice' (n.d.) Tate Website: http://www.tate.org.uk/art/art-terms/s/socially-engaged-practice (Accessed May 24, 2017)
} 
Four centuries after Descartes, we are still having trouble with the concept of mind-body dualism. The first problem arises from intellectualist tendency to regard body praxis as secondary to verbal praxis... [but in order] to discover the nature and sources of human meanings, we must explore our non-conscious bodily encounters with our world. ${ }^{15}$

The above quote delineates the imperative in exploring the role of our bodies in regards to meaning-making. It also alludes to an ontological issue concerning a physical methodology: the body is a language in-and-of-itself. Physical acts do not translate to something else, but use the grammar and syntax of themselves to make meaning of themselves. To translate a body's meaning-making — to document, to photograph an action, to video an event, to write about it - is to is to turn it into something else. What was once the language of the body becomes the language of the eye, or the brain: "Meaning should not be reduced to a sign which, as it were, lies on a separate plane outside the immediate domain of an act." ${ }^{16}$ This fact makes analysis and/or evaluation of physical experiences as art seemingly difficult, because to evaluate and/or to analyse suggests that we speak - as concept, as language, as historical narrative - about that experience; that it is translated into another contexts. In this sense, it is ostensibly problematic to derive a conceptual framework for a physical methodology in any discursive sense that is not physical. The solution to this problem lies in two fields that both involved developing an intellectual schema for a physical methodology: that of Embodied Cognition (EC) and an Anthropology of the Body (AoB).

Embodied Cognition argues that "embodiment seems to be at the root of seemingly disparate relationships between higher-order thoughts and basic bodily action." 17 It is a study that broadly recognises cognitive and identificatory processes are inherently 'embodied' - in other words, our understanding of the world primarily stems from the body's physical perceptions, and these in turn shape ontological frameworks. We make sense of the world via our similar perceptions of the world: humans, generally, are of similar shapes, with similar limbs, similar perceptual abilities, and similar biological limitations. This similarity of our sensorial physicality gives rise to general shared (social) understandings where "meaning emerges (mostly) automatically and without conscious awareness from the way we - as bodily creatures - engage with our surroundings. The fact of being embodied means that we are all subject to biological and physical events that move us, change our body states, and constrain thoughts and actions."18 Therefore, our shared physicality gives a base knowledge that requires no intellectual/conceptual translation because we are already all embodied and understand physicality tacitly. We may not be able to speak about physicality in a linguistic sense, but we do understand it because we have a shared physical base knowledge that is already physical.

While it cannot be questioned that physicality influences the sensory fields of our experience visio-spatial understanding, distance perception, perspective - Embodied Cognition theorists also explain that more complicated, higher mental and conceptual activities, including self-perception, memory, language comprehension, and reasoning, are also informed and framed by our physical selves, particularly by the sensory-motor system (i.e., the body). "Abstract meaning also appropriates the meaning and logical inference of a sensory-motor source to structure our understanding of some abstract notions... [and] the logic of our bodily experience provides all the logic we need to perform every rational inference we can make." ${ }^{19}$ In other words, to make 'meaning' of complex theories we speak of them via our bodies: a long way to go to understand (a body's knowledge of time and space); a rushed idea (speed); competitive theories (physical interaction), a weak proposition (strength). Physicality is therefore already part of our conceptual frameworks, and understanding physicality is embedded into cognitive processes.

\footnotetext{
15 M. Johnson. (2008) 'Body meanings', New Scientist, 12 January, pp. 46 - 47. p. 46.

${ }^{16}$ M. Jackson. (1983) 'Knowledge of the Body' Man New Series. 18:2 (June). pp .327-345. p. 328.

17 E. Balcetis \& S. Cole (2009) 'Body in Mind: The Role of Embodied Cognition in Self-Regulation' Social and Personality Psychology Compass 3:5. pp. 759-774. p. 762.

18 M. Johnson. (2008,) 'Body meanings', New Scientist, 12 January, pp. 46 - 47. p. 46.

19 Ibid. p. 47.
} 
Importantly to this text, there are also findings that suggest it is through these shared understandings of the way our bodies interact with the world that we are able to form social and relational bonds. This is not a passive process, but an active one wherein "body movements can trigger affective responses." 20 For example: "Nodding one's head leads to more positive evaluations of products and arguments, while shaking one's head leads to more negative evaluations." 21 In other words, to enact conscious physical actions can therefore affect mental processes in regards to how we interface with other people, and how they interact with us. Our physicality is therefore important in how humans understand their place in the world in regards to how we form, sustain or break relational bonds, much like Mirror Neurone processes, above.

That physicality is important in social interactions suggests that the physical can therefore be employed as an effective methodology when 'working with people' in Socially Engaged Art as this work also calls for affective bonding and understanding of shared processes. In other words, as the social sphere in all its complexities is based on physical readings of the self, the world and each other, the body is therefore a most useful tool to engage in that realm and its complexities, and can therefore be used by artists to developed aesthetic responses that can challenge perceptual habits. This obviously has applications within the context of performance art, as well, and here the body also becomes a main translation mechanism - a sort of 'Rosetta Stone' - through which interrelationships (i.e., society/community) can be formed, examined, broken, challenged or sustained, because it is a touchstone between all those with bodies which allows us to formulate concepts and social bonds.

To summarise thus far, Embodied Cognition provides a conceptual framework that links our mind to our bodies, and vice versa. It has revealed that our physicality is vital in how we read the world, how we speak about the world and how we are able to alter - and have altered - our fundamental conceptualisations. Embodied Cognition then points towards the understanding that our thinking is already based on schemas of 'bodiliness,' and to 'do' physical actions then can impact and alter thoughts or concepts about social bonds and the world. While this does not provide earth-shattering shifts in thinking about art in general - indeed questions of 'the body' has been a focus for decades - it does however suggest a methodology of engagement in participatory settings as it provides a mechanism through which to explore the social realm in all its complexities, while still being 'art'. In other words, considerations of how other forms of non-visual art - affectivity, performance, the sensorial and their engagement with Embodied Cognigiton - can be employed to socially engaged practices to provide new thinking about how this work is art. This is useful (and important) when doing 'art' in the public realm as it means physicality itself could be employed as a 'material' in order to inquire into the specific contexts of a community's being, thus by-passing complex language and conceptual processes or the traditional visual processes that are normally associated with 'art'. It therefore is already an integral part of the social realm and, as such, can be successfully employed as an artistic methodology to talk about complex social relations.

\section{2) The Anthropology of the Body}

Embodied Cognition frames the nuances of physical interactions; the Anthropology of the Body describes a wider social context in which these interactions take place. In a metaphorical sense, The Anthropology of the Body acts as the landscape on which actions of Embodied Cognition play out. Before this landscape is revealed, it is important to lay foundation on the relationship of Anthropology's relationship to art, particularly Socially Engaged Art. Both processes both share relationships with 'others' - other groups, other communities, other cultures - and also develop 'products' or 'documents' from those relationships - studies, papers, displays, artworks, objects, films, research, installations, concepts, and arguments. Problematically, both also have histories of colonisation, appropriation, racism and oppression, but space and time limitations will not allow sufficient address of those issues in any depth.

\footnotetext{
${ }^{20}$ E. Balcetis \& S. Cole (2009) 'Body in Mind: The Role of Embodied Cognition in Self-Regulation' Social and Personality Psychology Compass 3:5. pp. 759-774. p. 768.

21 lbid. p. 763.
} 
Briefly, and in specific relation to SEA, critic Hal Foster's article "Artist As Ethnographer" (1996) examines the 'alterity' approach of artists 'working with people', and evokes the radical call of Walter Benjamin for artists to be 'Producers' in a political and cultural sense in order to avoid the patronising approach of being a 'cultural benefactor'. Foster sees parallels with that call and the necessity of challenging the quasi-anthropological approach of SEA artists who claim a political and transgressive stance, but do so without examining the structures that sustain and support their positions as cultural authorities:

Just as the productivist sought to stand in the reality of the proletariat only to in part of sit in the place of the patron, so the quasi-anthropological artist [i.e., SEA practitioner] today may seek to work with sited communities with the best motives of political engagement and institutional transgression, only in part to have this work recorded by its sponsors as social outreach, economic development, public relations... or art. ${ }^{22}$

In this way, Foster, calls for an analysis of the intention of social artworks in order to understand how SEP functions. Foster's analysis of an anthropological approach - the "science of alterity... [based] on a primitivist assumption"23 - which ostensibly aims to critique power structures but "may actually reinforce [them] by positioning the anthropologist as the expert reader of cultureas-text," ${ }^{4}$ is therefore a resonant critique for SEA, too. He challenges artists to examine the "problems that arise when art tries to follow the ethnographic principles of participant-observer." 25

The critique of the 'participant-observer' is similar to the anthropologist Michael Jackson's critique of anthropological field work, and he developed the concept of the 'Anthropology of the Body'26 in response. Jackson argued for the 'knowledge of the body' as the primary site - and transmitter - of cultural knowledge, rather than social, religious or intellectual processes. Unlike Foster's article, however, Jackson was less concerned about the position of the artist in entering into an 'other' culture, (although, this is still an ethical concern for him, as for any practitioner working with 'others') but more about position of the body to others, specifically about the necessity of undergoing similar, shared physical experiences of the society in order to read and understand a different culture to one's own. He argues that it is physical experiences themselves that gave rise to understandings. He emphasised that the physical actions are not a representation of culture but were instead the very nature of the culture, and agreed with David Best that: "Human movement does not symbolise reality, it is reality." ${ }^{27}$ Indeed, this quote is a clue as to ways in which Anthropology of the Body offers new insights to the notion of the physical within artistic expression that of 'representation' vs. 'experiential'.

Jackson argued for a framework of understanding that was not based on speaking about - or representing - social interactions, but actually understanding the body on its own terms, and drew on the philosopher Merleau-Ponty who suggested bodily experience (via its senses and perceptions) was the primary mechanism through which one understands the world around us, as with Embodied Cognition, above. These perceptions could not be translated into another form (i.e. a visual, a semiotic, or intellectual framework) and this inability of translation meant that knowledge could only stem from a shared sensorial/corporeal understanding:

For by using one's body in the same way as others in the same environment, one finds oneself informed by an understanding which may then be interpreted according to one's own custom or bent, yet which remains grounded in a field of practical activity and thereby remains constant with the experience of those among whom one has lived. ${ }^{28}$

\footnotetext{
22 H. Foster. (1996) 'The Artist as Ethnographer' in H. Foster (1996) The Return of the Real. Cambridge: The MIT Press. p. 302.

${ }^{23}$ B. Hopkins' (2003) 'The Artist as Ethnographer - Annotations' Hopkins' The University of Chicago website. http://csmt.uchicago.edu/annotations/fosterartist.htm Winter (Accessed 11 January 2017)

24 Ibid.

25 Ibid.

${ }^{26}$ M. Jackson. (1983) 'Knowledge of the Body', Man New Series. 18:2. pp. $327-345$.

${ }_{27}$ M. Jackson. (1983) 'Knowledge of the Body' Man New Series. 18:2. pp. 327 - 345. p. 239. (Emphasis added).

28 M. Jackson. (1983) 'Knowledge of the Body' Man New Series. 18:2. pp. 327 - 345. pp. $340-341$.
} 
In other words, AoB posits that it is through shared physical experiences that can one find connections and begin to develop meanings with 'others', and rather than the 'work' residing in a visual (or even physical) representation - a performance, a document, a visual expression - the Anthropology of the Body formulates the understanding of the experience as an actual event. As experiential rather than representational. This experiential is based within a context of physical sharing and, again, that physical experiences provide the context to develop shared meanings with 'others' is highly useful when considering Socially Engaged Art, as this is the very premise of the practice. Important to consider is that this approach does not suggest that one cannot have an experiential, physical response to viewing an artwork - consider Rothko's large paintings or Ed Ruscha's Chocolate Room (1970) - but the difference lies in a shared meaning between bodies, not between the body and an object.

Jackson developed the approach in repose to a concern about ethical anthropological understandings - i.e. living and working with 'others' studied as part of anthropological fieldwork. However, it is also relevant when seeking to develop shared knowledge with any group that is not one's own. In this sense, physical interactions are the essential components when participating with others, as they are tools for understanding and knowledge-making between any groups or individuals which are based in equal and egalitarian approaches. In other words, it not just about understanding that 'other' culture, but also about the ethical ramifications of not understanding them appropriately. For Jackson, the AoB was a methodology which could be used both to resist and critique the colonial anthropological strategies of the past as well as a methodology through egalitarian physical experiences that an 'other' not only comes to understand a different culture, but also develop egalitarian relationships with them. It does not suggest that the physical should be the only 'true' understanding - the world is, after all, plural - but rather that representational works deny the affective knowledges that are provided by the shared, physical and actual event.

Indeed, the physical within the aesthetic realm is not a 'new' concept - consider the sensory arts and design movement ${ }^{29}$, or the following quote:

'Fine artists, and those given to enjoyment and criticism of visual arts ... are seen as exponents of the trained eye. They ... pretend to know how to look, and how to draw the highest semiological and visual satisfaction from that looking. Their total dependency on sight has almost entirely negated the senses of touch, hearing, taste and smell in an artwork'. ${ }^{30}$

Indeed, the concerns with the sensorial and phenomenological senses has been a key concern for theorists and critics of audio artists, or those working with smell, or touch, or even whole body movement, such as performance artists. What is AoB offers which is different is that the focus is not upon the phenomemlogical senses of the body, but rather the shared, experiential physicality as meaning making; of doing things together with our bodies. In other words, the focus is on the physical/experiential rather than the sensorial, and this shared, equal physical experience between bodies can be premised as ethical, egalitarian and a productive way to construct meaning.

Combining this approach with Embodied Cognition (EC), physical actions can then also be 'endpoints' in themselves (rather than just the materials for semiotic or intellectual paradigms) in that it is the corporeal itself which can provide new meanings, shared knowledge and the basis for ethical interrelationships: non-representative physicality as a methodology and object of artistic expression.

To conclude this section, according to EC, the (active) body can be understood as a mechanism through which interactions of knowledge, meaning-making, and understanding can occur physically - both in its tacit reading of the world around us, but also in its ability to communicate new meanings and challenge/question how the world is organised. Within the AoB approach, having

${ }^{29}$ See, for example,I. Haywood (2017) ed Sensory Arts and Design. Bloomsbury Academic: London.

${ }^{30}$ W. Boshoff, (1997) 'Aesthetics of touch: notes towards a blind aesthetic', Image and Text 7, Issue: 36, 
similar physical experiences as the people he/she are working with, allows one (anthropologist or artist) to read - and have an understanding of — the culture within one is based, and thus the potential for an ethical exchange with 'others.' Eliding AoB with EC provides a context for shared meaning-making in that such an approach does not focus on 'representation' (i.e. documentation, or objects such as artworks) but rather the immediate physical exchanges, and the shared, ethical meaning-making that occurs within those exchange (which also resist colonial approaches that might emerge out of traditional gallery/museum and/or anthropological strategies).

\section{3) Physicality As Aesthetic Framework Within Socially Engaged Artworks}

To return this to the context of my work, much like Jackson's Anthropology of the Body, my work occurs in a 'residency' format - i.e., carried out onsite and within communities. Within residencies, I can physically and collaboratively engage in the rituals, the movements, the tacit and kinetic understandings, how the communities were physical with each other, and thereby develop not only a deeper understanding of the social realm, but also foster deeper and more egalitarian relationships, as I too am experiencing similar things. My physical presence and engagement is essential to the participatory nature the engagement and in this work I seek to employ the body in ethical co-creation based on an aesthetics of physicality (rather than for the creation of objects). I will now discuss one example which applies the above concepts, beginning with a brief background contextualisation.

In 2013 I was invited by the local museum (Timespan) to develop a 3-month Socially Engaged Art project with the community in the North of Scotland to creatively examine the impact of the Highland Clearances, 200 years after the first farmers were forced off their lands. There is insufficient space in this text to describe and explain every nuance of my project and how the knowledges emerged, and so I will focus on the final project, and the steps I took to get there.

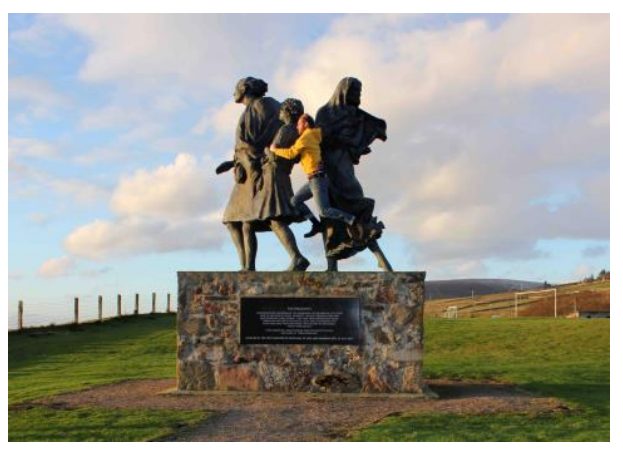

Fig 1.5 Climbing on Helmsdale's The Emigrants statue, Photographic documentation. January 2013.

Helmsdale, Sutherlandshire, is in the far north of Scotland. It is a small seaside village of 600 people, built in the early-to-mid-1800s to accommodate the tenant farmers evicted from their lands as part of the Highland Clearances. The main source of income to the village is tourism, though it is seasonal and inconsistent, and the area faces many of the challenges that other settlements in the North of Scotland face, such as the collapse of the traditional fishing industry due to large-scale industrialisation of the sector elsewhere, leading to high unemployment. Additionally, opportunities in the North Sea Oil industry are too far away for a feasible commute, and a lack of local opportunities for employment drives an exodus of the villagers to bigger cities (in particular Aberdeen and Inverness). ${ }^{31}$ The main stabilising force within the village in recent years has been a large influx of settlers (mostly from England) who have immigrated to the village, seeing it a more desirable place to raise children, to be closer to nature, and to take advantage of property values and quality of life. This influx, however, has led to tensions between those who see themselves as 'local' and those who are viewed as 'incomers' ${ }^{32}$ — this latter group are not seen to value or

31 T. Pateman. (2010) 'Rural and urban areas: comparing lives using rural/urban classifications'. Office for National Statistics. Regional Trends 43. \& 'Review of Scotland's Cities - The Analysis' Scottish Executive, 2002. B26917-12-02 ${ }^{32}$ An example of this would be conversations I had with local crofter Crispin who has lived in the area for 47 years and is still referred to as an 'incomer.' How much of this is a self-claimed and a perceived dispute versus an actual and problematic experience is rather difficult to unpick. Regardless, the divisions exist and have social ramifications. 
understand the traditional way of life, nor fully comprehend the heritage of the area, specifically, the importance of the Highland Clearances. This importance relates to both cultural heritage - and therefore identity - but also the economic contribution that the historical events brings to the village as many international visitors (including many descendants from this village who settled in Canada after the Clearances) come to explore their ancestors and the history of these events, not to mention educational tours, academic and artistic research that focus on the Clearances which all contribute to the economics of the village.

At the start of my project, I spent several days acclimatising to village life and researching the museum's collection before going out to meet the villagers. Much of this work included joining local clubs, talking to people in pubs, walking people's dogs with them, talking to people doing their shopping etc: i.e., living with the community. Over time, these developed into more formal exchange, such as guided walks, presentations, temporary exhibitions, discussions and recreations of historical events. These formal and informal activities resulted in a clear understanding that the villagers broadly fell into two camps: those that felt 'The Clearances Are Still Happening' and those that felt the 'Clearances Are Over'. The former felt that the legacy of these historical events were the most important cultural topic and a vital historical event that still affected the village today. The latter group felt that the Highland Clearances, while important, was merely one historical event out of the past 5000 years of human habitation in the area, and other topics also deserved exploration. The division in groups also appeared to be divided along the same lines as the 'locals' and 'incomers', too, and so my project began to explore concept of this cultural/social division and how it played out in the public sphere.

Chantal Mouffe suggests that "public spaces are the ...the battleground in which different hegemonic articulations are confronted...they are plural... where there always exists a multiplicity of struggle." 33 In other words, no public sphere or community can be without conflict and discord of some sort, and multiplicity and oppositions of hegemonic orders are an inherent part of human society. Mouffe argues, however, that is is important for art to "make visible what the dominant consensus tends to obscure and obliterate, giving voice to all those who are silenced within the framework of the existing hegemony." ${ }^{4}$ The latter 'The Clearances Are Over' camp appeared to have few mechanisms to express their views due to the dominant hegemony of the 'The Clearances Are Still Happening' group, reenforced by organisations such as the local Museum. Additionally, there were few formal instances where the groups interfaced (they kept quite separate 'camps') and their different perspective was quite 'invisible' within the community. Therefore, I began looking for ways for the groups to interact more which might illuminate and examine their different perspectives. As Lynch suggests: "as relational beings, humans can only ever successfully learn about themselves through engagement with another." 35 In other words, we make sense of the world by rubbing up against those parts of the world that are not us, finding out where we end and they begin. If, however, there are few opportunities for this collision with 'the other' to occur, then this reflective analysis cannot occur and so I wanted to develop a project that used physical methodologies to address the lacks of forums for exchange.

As with most artistic experiences, the solution to this problem was quite serendipitous, and came in the form of Shinty. Shinty is a stick-and-ball game derived from the Irish sport Hurling, and probably came to Scotland in the early part of the 1 st century C.E.. A traditional part of Highland culture, it waned in the latter half of the 20th Century, but in the wake of Scottish Independence has seen a resurgence. Today, the traditional game is mostly played in the Highlands, in the Shinty League, and although Helmsdale has not contributed a team for over 20 years, it is still played casually and the school even offers it as part of Physical Education Lessons. It also has a link with the Clearances in Helmsdale as the yearly Old New Year game of 1813 was been documented as being moved and extended in order to spy on the Highland Clearance officials (William Clunes).

\footnotetext{
${ }^{33}$ C. Mouffe. (2007) 'Agonistic Politics and Artistic Practices' (Lecture) Glasgow School of Art, Glasgow, 2nd March.

${ }^{34}$ C. Mouffe. (2013) Agonistics: Thinking the World Politically. Verso, London. p. 93

35 B. Lynch, as quoted by V. Hollows. (2013) 'The Performance of Internal Conflict and the Art of Activism.' Museum Management and Curatorship. 28:1. pp. $35-53$.
} 
Shinty sticks were also used in the Kildonan Riots that chased Clunes and other officials from off the farmer's lands. ${ }^{36}$

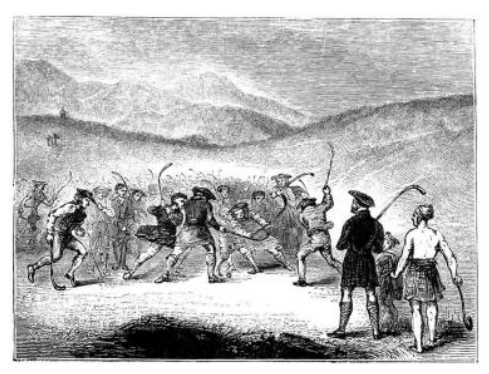

Fig 1.6 Untitled Shinty Illustration from Penny Magazine, London. Published 1823.

I realised that this ancient, traditional game could be applied as a useful physical methodology through which I could merge the historical issues of the Clearances with contemporary issues raised during the course of my residency: the notions of 'incomer' or 'local' (which, co-incidentally, seemed a modern parallel to the trans-migratory issues of the Clearances). Additionally, I felt the binary divisions and combative relationship between the 'incomer' and 'local' aligned neatly into the format of a physical, 2-sided sporting game and felt the game could be positioned as a forum by which to explore their clashes. In other words, the game would give two groups that rarely interacted a chance to live-out their conflict in a 'known' and mediated format - not as a catharsis, but a physical metaphor for the social experience. Lastly, the game functioned because of each groups' belief and distinct identity - i.e., their ideological oppositions drove the forum of the competition.

I therefore scheduled a shinty match between 'incomers' and 'locals'. Various 'build-up' events were planned, such as playing a game on the original site of the Old New Years Game 1813 (Shinty! The Old Ways! - Fig 6.7), or beginning an extra-curricular club with the school to practice. These were done both for marketing and to engage the community in the concept, but also to build up team-members for the final event. Other surrounding activities included working with the local Youth Club, to design the icons/logos and names for each teams (The Sutherland Raiders - see Fig 6.8 - and The Incoming Riot). The final event took place in March and consisted of a bagpipeled parade from the centre of the town to the town's sports fields, where the game was played for 40 min each half in the sleeting hail and snow, while the rest of the town looked on from the warm comfort of the clubhouse. The final score was 3 to 6 for the Sutherland Raiders (i.e., the 'locals')
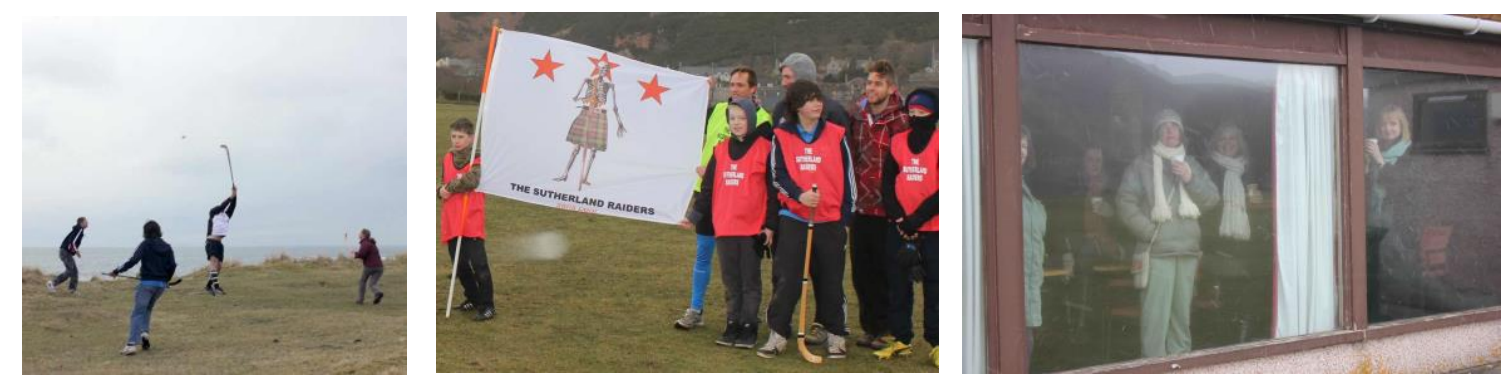

Fig 1.7 Shinty! The Old Ways, Photographic documentation. March 2013. Fig 1.8 Shinty! The New Ways, Photographic documentation. March 2013. Fig 1.9 Shinty! The New Ways, Photographic documentation. March 2013.

The Anthropology of the Body approach (i.e., a residency) allowed the work to emerge, as it was only through the embedded living with communities that was able to understand the context and nuances of the diverse social interactions. The game applied Embodied Cognition notions which allowed the format of the physical combative game to provide conceptual metaphors for the clashes, and along with the tacit understands of physicality, provided a forum to make visible the

36 J. Prebble. (1963) The Highland Clearances. London. Penguin Books. 
hidden conflicts between hegemonies. These, tied with the historical nature of the Shinty game, entrenched the discussion into a culturally historical narrative. The physical nature of the game, therefore, became essential in how the perceptual habits of the entire village - and its relationship to events that happened 200 years ago - could be challenged and called into question. In the definition provided above by Magor, this game is defined as 'art' in that it was a non-visual exploration of identities, cultures and forums of productive exchange.

To be clear, the intention of the project was not to be ameliorative; it was not premised on 'fixing' a relationship. On the contrary, the distinction between their hegemonic orders was the very reason they engaged in the competition and why the event functioned productively. It was because of their difference that they engaged, and agonistically, they became committed to the same cause: winning the game. It was a physically enacted metaphor of the hegemonic challenges that occurred daily between these two groups. In this sense, the physicality of the game managed to reveal in what ways the community were segregated into separate spheres, and an opportunity to develop new relationships with each other. This revelation and enacted/embodied metaphor allowed those engaging or watching the event to play "an active part in a project which effectively recreates the world... allowing each person to discover in his or her own personality a way of producing, out of the momentary chaos, something which will contribute to the renewal of the social order." 37

Similarly, the audiences watching from a distance became invested in the concept via the Mirror Neurone process (understanding by doing, by imitation, and by physical observation) and therefore also entered into the physical/embodied conceptual processes.

The project aimed to provide new insights into the social order of a community via giving an alternative form of its expression - i.e. a physically form. This alternative way explored the topic successfully because it was predicated upon tacit, physical and personal corporeal understandings, rather than mental or intellectual processes. The understandings were lived and not represented in images or traditional seen/looked at art. In other words, the participants and the viewers were not engaging in the topic inside a museum/gallery, reviewing pedagogical or abstracted positions, but in a real-time, cold and blustery field, and the physical methodology gave alternative entry points into topic of the Highland Clearances and the subsequent incomer/local dichotomy. In this sense, the physical offered an innate and immediate comprehension that could provide an effective challenge of perceptual habits.

\section{3) Conclusion: Seeing The World With Our Bodies.}

Many years ago, I was invited to deliver a lecture to group of art students on Socially Engaged Art. I decided to title the talk "The Tyranny of Vision" as I wanted to impress upon the students that instead of perpetuating the habits of the visual, the physical provided a pre-existing context for art which did not defer to Greenbergian or Modernist habits of the eye. Furthermore, this methodology already existed - was primed and ready for application — within the communities in which Socially Engaged Artists worked. At the end of this lecture, a student asked if I was therefore suggesting that artists should stop making things to 'look at'?

My concern then - as with now - was that I had not explained myself clearly: I told her that I still made things to look at: For example, the majority of the community of Helmsdale still looked at the Shinty game, only a few of them 'played' it. Indeed, even 'looking' at traditional art is a physical process - the eye is part of our body, so we cannot separate the experience of art from eye, from looking. Instead, the point I was making (and the point with which I wish to conclude here) is that the visual is not the only way of making-meaning in the world. Neither does it need to be the default definition of art; nor would I suggest physical ontologies are 'better' than visual or other traditional ways of making art with people. Instead, what I am suggesting is that the physical has been a more useful, accessible and immediate tool within Socially Engaged Art (SEA) because of the visual hangover of Greenberg and Modernism. In other words: SEA occurs with people in-and-amongst the daily lived of lived society, and in most of these contexts there is an assumption that art is a visual medium. This causes a disjunct between the artist and a community about how 'art' can

${ }^{37}$ M. Jackson. (1983) 'Knowledge of the Body’. Man New Series. 18:2. pp. 327 - 345. p. 330. 
occur, as most people don't feel they can draw or paint or sculpt or make visual art. However, if Socially Engaged Artists approached their work via a physical ontology that positions the body as a common entry point (a sort of Rosetta Stone) between communities, between artist and non-artists, between the 'self' and the 'other', then these approaches provide a context by which to make artworks with a much larger cross-section of communities. In other words, the visual — like me and my poor eye-sight - has a tendency to exclude if it is presented as the only way to make art. Embodied Cognition and The Anthropology of the Body provide an explanation of how we are already physical creatures, therefore a physical methodology can easily, ethically and effectively be applied to make art with communities in ways that visual art cannot. This does not mean there is nothing to 'look' at, but that the work - either in process or in documentation - can be accessed through our bodies, as well as our eyes, either through affective shared physical experiences, or through processes such as mirror nurones. This is not a claim that it the only process by which to enact participatory works - there are, after all, people who are more visually inclined than others within all communities! - but rather than it is an effective process worth considering within this creative approach.

Nor does it mean that physical works need to be as bombastic as the Human Piñata or a Shinty game: indeed, it is vital to note that throughout this text I recognise and understand that there are multiple, complicated and subjective experiences of the body's interface with the world - consider (dis)ability, alternative sensitivities, different capabilities - and more research within the field of Embodied Cognition needs to be done to explore these diversities of corporeal experience. However, the point I am trying to emphasise is that it is the body itself that is the main and central interface to the external world, and we all have bodies, even if they are all different. It is this interface that I speak about when I am emphasising the 'universality' of the corporeal experience, not the subjective experiences themselves: that the body is a main translation mechanism between ourselves, the world and other people. In this regard, physical ontologies becomes an effective and affective - tool when working in genre of art that is fundamentally based on humans exchanging with each other in a process meaning-making.

\section{Bibliography}

A. Alvarez. (2012) 'Sedentary lifestyle not to blame for obesity' Journal Sentinel. http://www.jsonline.com/news/health/sedentary-lifestyle-not-to-blame-for-obesity-2868cb8-163809356.html. July 26, 2012. (Accessed 12 January 2017)

E. Balcetis \& S. Cole (2009) 'Body in Mind: The Role of Embodied Cognition in Self-Regulation' Social and Personality Psychology Compass 3:5. pp. 759-774

E. Belfiore (2002) 'Art as a means of alleviating social exclusion: Does it really work? A critique of instrumental cultural policies and social impact studies in the UK' International Journal of Cultural Policy, 8:1. pp. 91 - 106.

W. Boshoff, (1997) 'Aesthetics of touch: notes towards a blind aesthetic', Image and Text 7, Issue: 36,

The City of Edinburgh Council (n.d.) 'Edinburgh's Budget Challenge' Edinburgh Council Website: https://consultationhub.edinburgh.gov.uk/cg/budget/ (Accessed May 25, 2017)

B. Farnell. (2012) 'Theorising "the Body" in Visual Culture' in M. Banks and J Ruby (eds). University of Chicago Press: Chicago

J. Ferrer. (ed). (2009) The Participatory Turn: Spirituality, Mysticism, Religious Studies. Suny Press: Albany, NY 
H. Foster. (1996) 'The Artist as Ethnographer' in H. Foster (1996) The Return of the Real. Cambridge: The MIT Press. p. 302.

C. Greenberg. (1960) Forum Lectures. Washington, D. C.: Voice of America.

C. Greenberg. (1993) 'Sculpture in our time,' in J. O'Brian (ed.)1993 C. Greenberg, Collected Essays and Criticism, Volume 4. Chicago: The University of Chicago Press.

S. Hope. (2012) Participating in the 'Wrong' Way? Practice Based Research into Cultural Democracy and the Commissioning of Art to Effect Social Change. PhD Thesis. University of London. London

B. Hopkins' (2003) 'The Artist as Ethnographer - Annotations' Hopkins' The University of Chicago website. http://csmt.uchicago.edu/annotations/fosterartist.htm Winter (Accessed 11 January 2017)

M. Jackson. (1983) 'Knowledge of the Body’ Man New Series. 18:2 (June). pp .327-345.

M. Johnson. (2008) 'Body meanings', New Scientist, 12 January, pp. 46 - 47. p. 46.

S. Lees, \& F. Booth. (2004) 'Sedentary Death Syndrome'. Canadian Journal of Applied Physiology, 2004, 29:4. pp. $447-460$.

R. Levitas. (2002) New Labour and Social Inclusion: Citizenship and Social Exclusion Panel. University of Bristol, Bristol.

B. Lynch, as quoted by V. Hollows. (2013) 'The Performance of Internal Conflict and the Art of Activism.' Museum Management and Curatorship. 28:1. pp. 35 - 53.

M. Martinez-Gonzalez, J. Martinez, F. Hu, M. Gibney, J. Kerney, (1999) 'Physical inactivity, sedentary lifestyle and obesity in the European Union.' International Journal of Obesity Related Metabolic Disorders. 23:11. pp. $1192-1201$.

C. Mouffe. (2007) 'Agonistic Politics and Artistic Practices' (Lecture) Glasgow School of Art, Glasgow, 2nd March.

C. Mouffe. (2013) Agonistics: Thinking the World Politically. Verso, London.

G. Rizzolatti \& M. Fabbri Destro (2008) 'Mirror Neurones' Scholarpedia, 3(1): pp 2055.

Environmental Protection Agency (n.d.) 'Public Participation Guide: Introduction to Public Participation' Environmental Protection Agency website: https://www.epa.gov/international-cooperation/public-participationguide-introduction-public-participation (Accessed May 25, 2017)

T. Pateman. (2010) 'Rural and urban areas: comparing lives using rural/urban classifications'. Office for National Statistics. Regional Trends 43. \& 'Review of Scotland's Cities - The Analysis' Scottish Executive, 2002. B26917-12-02

D. Peterson (n.d.) 'Mirror Neurons \& Athletes: Learning by Watching'. Axon Potential. http://www.axonpotential.com/mirror-neurons-and-athletes. (Accessed 12 January, 2017)

J. Prebble. (1963) The Highland Clearances. London. Penguin Books.

S. Saurugger, (2010) 'The social construction of the participatory turn: The emergence of a norm in the European Union'. European Journal of Political Research. Volume 49, Issue 4. Pages 471-495.

Tate (n.d.) 'Socially Engaged Practice'. Tate Website: http://www.tate.org.uk/art/art-terms/s/socially-engagedpractice (Accessed May 24, 2017) 